\title{
A retention loss following septal ablations in the rat
}

ROBERT J. CAREY

SYRACUSE VA HOSPITAL AND STATE UNIVERSITY OF NEW YORK UPSTATE MEDICAL CENTER

Bilateral septal ablations in rats increased resistance to extinction when made before training, but decreased resistance when made after training. These contrasting effects were considered to demonstrate that septal ablations affect retention as well as performance.

It has been consistently reported that septal ablations in rats and cats disrupt preoperatively conditioned behavior (Brady \& Nauta, 1953; Tracy \& Harrison, 1956; Ellen \& Powell, 1962; Schwartzbaum, Kellicutt, Spieth, \& Thompson, 1964; Moore, 1964; Rich \& Thompson, 1965; Harvey \& Hunt, 1965; Harvey, Lints, Jacobson, \& Hunt, 1965; Carey, 1966). Whether these effects represent a retention or memory loss or are only secondary to possible motivational (Harvey et al, 1965; Kenyon \& Krieckhaus, 1965) and motor disinhibitory (McCleary, 1961) effects of septal damage, however, remains uncertain. The purpose of this experiment was to study the effect of septal ablations on the retention of a preoperatively trained response in which a retention deficit would be expected to have an opposite effect from motivational or motor disinhibitory changes associated with this lesion. It was thought that this could be accomplished by comparing the effects of septal ablations made before and after training of a water-reinforced lever-pressing response on the subsequent resistance to extinction of this response. A retention loss of the bar-pressing habit following septal ablations made after training should tend to reduce responding in extinction; whereas, either an increase in motivation or decrease in inhibition should tend to increase resistance to extinction regardless of whether the lesion preceded or followed training. The degree to which the response output is lower in animals ablated after training was expected to indicate the effect of septal damage on retention.

Method

The Ss were 20 male Sprague-Dawley rats 120 days old. Following $23-1 / 2-\mathrm{hr}$. water deprivation each animal was first trained to press a lever for $.1 \mathrm{cc}$ of tap water in an enclosed operant test chamber. After lever pressing was shaped, each animal received 50 reinforcements on a CRF schedule for three successive days. Sixteen days after the final reinforcement session, all animals were deprived of water for $47-1 / 2$ hr. and returned to the test chamber for $30 \mathrm{~min}$. during which lever pressing was recorded but not reinforced. This session was the extinction test. For Group I $(\mathrm{N}=10)$ all the animals were operated the day following the last reinforcement session so that 14 days intervened between the operation and the extinction test. The animals in Group $2(\mathrm{~N}=10)$ were operated 14 days before lever training was initiated. The operated animals in Group 1 were handled several times before the extinction test in an effort to diminish the irritability reactions of the animals with septal ablations in this group to a level comparable with those in Group 2 before the extinction test.

\section{Surgery and Histology}

One-half of the animals in Groups 1 and 2 received bilateral septal ablations. The lesions were made with a Grass LM 3 radio frequency lesion maker. The current was passed between a .022-in. stainless steel electrode tygon-insulated except for $.3 \mathrm{~mm}$ at the tip stereotaxically oriented into the septal area and a rectal electrode. The remaining 10 animals in Groups 1 and 2 were subjected to an identical operative procedure except that the electrode was only lowered into the cortex (1.5 mm below dura) and no current was passed. At the end of the experiment each animal's brain was fixed with $10 \%$ formalin, embedded in paraffin and cut into 10 micron sections. Destruction was reconstructed from sections saved at $.1 \mathrm{~mm}$ intervals which were stained cresyl violet. Examination of the lesions showed that they were fairly uniform between groups and among animals and were well confined to the septal area. In most cases, more than $80 \%$ of the medial and lateral nuclei were bilaterally destroyed.

Results

Table 1 presents the total number of responses emitted by each of the four operated groups in the $30 \mathrm{~min}$. extinction test. For animals operated after training, the response output of the septal ablated animals was always below that of the operated controls. This difference was highly significant, $p<.01$ (two-tailed Mann-Whitney $U$ test). The effect on extinction responding of septal ablations made before training was also significant $(p<.05)$ and in an opposite

Table 1. The number of responses emitted in the extinction test

\begin{tabular}{ccccc} 
Ss & $\begin{array}{c}\text { Septal } \\
\text { Operated } \\
\text { before } \\
\text { training }\end{array}$ & $\begin{array}{c}\text { Operated } \\
\text { after } \\
\text { training }\end{array}$ & $\begin{array}{c}\text { Operated Controls } \\
\text { Operated } \\
\text { before } \\
\text { training }\end{array}$ & $\begin{array}{c}\text { Operated } \\
\text { after } \\
\text { training }\end{array}$ \\
\hline 1 & 97 & 0 & 37 & 56 \\
2 & 107 & 5 & 61 & 63 \\
3 & 221 & 23 & 80 & 82 \\
4 & 246 & 29 & 100 & 117 \\
5 & 395 & 30 & 171 & 140 \\
\hline
\end{tabular}


Table 2. The mean number of responses emitted in successive 10 min. periods in the extinction test

\begin{tabular}{|c|c|c|c|c|}
\hline \multirow[b]{2}{*}{$\begin{array}{l}\text { Successive } \\
10 \text { minute } \\
\text { periods }\end{array}$} & \multicolumn{2}{|c|}{ Septal } & \multicolumn{2}{|c|}{ Oper ated Controls } \\
\hline & $\begin{array}{l}\text { Operated } \\
\text { before } \\
\text { training }\end{array}$ & $\begin{array}{l}\text { Operated } \\
\text { after } \\
\text { training }\end{array}$ & $\begin{array}{c}\text { Operated } \\
\text { before } \\
\text { training }\end{array}$ & $\begin{array}{l}\text { Operated } \\
\text { after } \\
\text { training }\end{array}$ \\
\hline 1 & 124 & 12 & 59 & 48 \\
\hline 2 & 59 & 3 & 21 & 30 \\
\hline 3 & 28 & 1 & 10 & 16 \\
\hline
\end{tabular}

direction from septal ablations made after training. Table 2 shows that all groups exhibited a similar pattern of decreased responding during the extinction period.

\section{Discussion}

The contrasting effects on extinction responding of septal ablations made before and after reinforcement training shows that septal ablations have a significant effect on retention which is distinct from an effect on motivation or inhibition. This effect on retention was only partial, however, and only represented a weakened tendency to perform the operant response since observation of four of the animals with lesions in the septal area which did respond in extinction showed that they pressed the lever in the same deliberate manner as the controls (i.e., they would press the lever and then immediately go to the water cup), but only less frequently. Since a stimulus generalization decrement typically represents a diminished tendency to perform a response as a result of a modification of the stimulus conditions, this effect of septal damage on retention may only mean that septal ablations result in new stimuli (e.g., irritability reactions) which are able to modify a test situation sufficiently to result in a stimulus generalization decrement. A retention loss, however, clearly needs to be taken into account in evaluating the effects of septal ablations on preoperatively trained behavior.

\section{References}

Brady, J. V., \& Nauta, w. J. H. Subcortical mechanisms in emotional behavior: affective changes following septal forebrain lesions in the albino rat. J. comp. physiol. Psychol., 1953, 46, 339-346.

Carey, R. J. Effects of rhinencephalic ablations on DRL responding in the rat. Unpublished doctoral dissertation, University of Chicago, 1966.

Ellen, P., Powell, E. W. Effects of septal lesions on behavior generated by positive rinforcement. Exp. Neurol., 1962, 6, 1-11.

Harvey, J. A., \& Hunt, H. F. Effect of septal lesions on thirst in the rat as indicated oy water consumption and operant responding for water reward. J. comp. physiol. Psychol., 1965, 49-56.

Harvey, J. A., Lints, C. E., Jacobson, L. E., \& Hunt, H. F. Effects of lesions in the septal area on conditioned fear and discriminated instrumental punishment in the albino rat. J. comp. physiol. Psychol., 1965, 59, 37-58.

Kenyon, J., \& Krieckhaus, E. E. Decrements in one-way avoidance learning following septal lesions in rats. Psychon. Sci., 1965, $3,113-114$

Mccleary, R. A. Response specificity in the behavioral effects of limbic system lesions in the cat. J. comp. physiol. Psychol., $1961,54,605-613$.

Moore, R. Y. Effects of some rhinencephalic Iesions on retention of conditioned avoidance behavior in cats. J. comp. physiol. Psychol., 1964, 65-71.

Rich, 1., \& Thompson, R. Role of the hippocampo-septal system, thalamus, and hypothalamus in avoidance conditioning. $J$. comp. physiol. Psychol., 1965, 59, 66-72.

Schwartzbaum, J. S., Kellicutt, M. H., Spieth, T. M., \& Thompson, J. B. Effects of septal lesions in rats on response inhibition associated with food reinforced behavior. J. comp. physiol. Psychol., 1964, 58, 217-224.

Tracy, W. H., \& Harrison, J. M. Aversive behavior following lesions of the septal region of the forebrain in the rat. Amer. J. Psychol., $1956,69,443-447$. 